\title{
Inhibitory effect of Phenethyl Isothiocyanate Against Benzo[a] Pyrene-Induced Rise in CYP1A1 mRNA and Apoprotein Levels as its Chemopreventive Properties
}

\author{
Ahmad Faizal Abdull Razis ${ }^{1,2 *}$, Nattaya Konsue ${ }^{3}$, Costas Ioannides ${ }^{4}$
}

\begin{abstract}
Background: Phenethyl isothiocyanate (PEITC), the most comprehensively studied aromatic isothiocyanate, has been shown to act as an anti-cancer agent mainly through modulation of biotransformation enzymes responsible for metabolizing carcinogens in the human body. Humans are often exposed to carcinogenic factors, some of which through the diet, such as polycyclic aromatic hydrocarbon benzo[a]pyrene via the consumption of over-cooked meats. Inhibition of the enzymes responsible for the bioactivation of this carcinogen, for example CYP1A1, the major enzyme required for polycyclic aromatic hydrocarbons (PAHs) bioactivation, is recognized as a chemoprevention strategy. Objective: To evaluate the inhibitory effects of PEITC against benzo[a]pyreneinduced rise in rat liver CYP1A1 mRNA and apoprotein levels. Materials and Methods: Precision cut rat liver slices were treated with benzo[a]pyrene at 1 and $5 \mu \mathrm{M}$ in the presence of PEITC (1-25 $\mu \mathrm{M})$ for 24 hours, followed by determination of CYP1A1 mRNA and apoprotein levels using quantitative polymerase chain reaction and immunoblotting. Results: Findings revealed that PEITC inhibited benzo[a]pyrene-induced rise in rat liver CYP1A1 mRNA in a dose-dependent manner as well as the apoprotein levels of CYP1A. Conclusions: It was demonstrated that PEITC can directly inhibit the bioactivation of benzo[a]pyrene, indicating chemopreventive potential.
\end{abstract}

Keywords: Polycyclic aromatic hydrocarbons - benzo[a]pyrene - phenethyl isothiocyanate - chemoprevention.

Asian Pac J Cancer Prev, 16 (7), 2679-2683

\section{Introduction}

Human are exposed to chemical carcinogens almost on daily basis. Major sources of these compounds are, for example, polycyclic aromatic hydrocarbon (PAH) derived from tobacco and cooked-food (Hecht, 2003), and other food-derived carcinogens such as heterocyclic amines (HCAs) and nitrosamines (Boyce et al., 2014). In most cases, bioactivation of chemical carcinogens is prerequisite for the formation of electrophiles which form DNA adducts leading to carcinogenesis. Inhibition of the enzymes responsible for the bioactivation of carcinogens such as CYP1A1 and 1A2, the major enzymes required for PAH and HCA bioactivation, respectively (Kobayashi et al., 2009; Wohak et al., 2014) is recognized as a chemoprevention strategy (Liu et al., 2013). Accordingly, the ability of glucosinolates and isothiocyanates (ITCs) to prevent the formation of genotoxic metabolites through modulation of carcinogen-metabolizing enzymes has recently attracted extensive interest worldwide. It has been reported that drinking water supplemented with glucosinolate-rich vegetables, such as Brussels sprouts and red cabbage, reduced IQ-mediated preneoplastic lesions in F344 rats which was accompanied by induction of hepatic UDPGT and CYP1A2 activities (Kassie et al., 2003). Sulforaphane and its synthetic analogues down-regulated CYP1A2 and directly inhibited CYP1A1-induced activity by benzo[a]pyrene in human cell line (Skupinska et al., 2009).

It has been proposed that PEITC, isolated from watercress, is a potent anti-carcinogen in chemicallyinduced models of cancer (Kuroiwa et al., 2006). The chemoprevention properties of this isothiocyanate is attributed via a series of mechanisms involving a reduction in the appearance of the toxic metabolites of carcinogens by defeating cytochrome P450-stimulated bioactivation and/or promoting detoxifying enzymes (Konsue and Ioannides, 2008; 2010a, 2010b; Abdull Razis et al., 2011; Devi and Thangam, 2012; Abdull Razis and Mohd Noor, 2013a, 2013b; Abdull Razis et al., 2014). Indeed of its positive react to phase II detoxifying enzymes, its response to phase I cytochrome P450 1A1 is remain unclear. Earlier studies revealed that PEITC is able to modulate CYP1A1 mRNA in rat and human liver (Abdull Razis et al., 2011).

${ }^{1}$ Food Safety Research Centre (FOSREC), Faculty of Food Science and Technology, ${ }^{2}$ Laboratory of UPM-MAKNA Cancer Research, Institute of Bioscience, Universiti Putra Malaysia, UPM Serdang, Selangor, Malaysia, ${ }^{3}$ School of Agro-Industry, Mae Fah Luang University, Mool Thasud Muang, Chiang Rai, Thailand, ${ }^{4}$ Molecular Toxicology Group, Faculty of Health and Medical Sciences, University of Surrey, Guildford, Surrey, UK *For correspondence: madfaizal@upm.edu.my 
Moreover, PEITC has increased CYP1A1 protein and decrease enzymatic activity of CYP1A1 indicating that this aromatic isothiocyanate elicits chemopreventive activity through a mechanism based-inhibition (Konsue and Ioannides, 2010a). Thus, the inhibition of benzo[a] pyrene-induced rise in CYP1A1 expression level is considered to be a helpful biomarker of chemopreventive potential of PEITC. In addition, an established association between modulation of cytochrome P450 1A1 and cancer has been noted (Williams et al., 2000). Therefore, the overall objective of the present study was to evaluate the inhibitory effect of PEITC against benzo[a]pyreneinduced rise in rat liver CYP1A1 mRNA and apoprotein levels.

\section{Materials and Methods}

\section{Materials}

Phenethyl isothiocyanate (PEITC), benzo[a]pyrene, Goat anti-mouse polyclonal antibodies (Sigma Co. Ltd., Poole, Dorset, UK), anti-CYP1A1 monoclonal antibodies (AMS Biotechnology, Abingdon, UK), rat genomic DNA (Novagen, Wisconsin, USA), RNase-free DNase, DNase stop solution, DNase buffer (Promega, Wisconsin, USA), Nucleospin ${ }^{\circledR}$ RNA II (Macherey-nigel GmbH \& Co, Düren, Germany), RPMI 1640, Earle's balanced salt solution (EBSS), Minimum Essential Medium Alpha (MEM- $\alpha$ ), gentamicin, fetal calf serum, Superscript II reverse transcriptase, random hexamers, RNase OUT, RNase-free water, and dNTP mix (Invitrogen, Paisley, Scotland), AbsoluteTM QPCR Mix (Abgene, Epsom, Surrey, UK), were purchased.

\section{Rat liver samples}

The study was conducted according to the Animals (Scientific Procedures) Act 1986. Male sex Wistar albino rats (200-250 g) were bought from B\&K Universal Ltd (Charles River, Margate, Kent, UK). These animals were caged at a relative humidity of $30-40 \%, 22 \pm 2{ }^{\circ} \mathrm{C}$, with an alternate 12-h light: dark cycle with light starting from $07.00 \mathrm{~h}$.

\section{Precision-cut rat liver slices preparation and incubation}

Liver slices (200-300 $\mu \mathrm{m})$ were set from $8 \mathrm{~mm}$ cylindrical cores using Krumdieck tissue slicer (Alabama Research and Development Corporation, Munsford, AL, USA) as was earlier developed by Hashemi et al. (1999). A 12-well plate was employed to culture the slices with one slice was resided in each well followed by incubation in $1.5 \mathrm{ml}$ media containing test compounds at $37^{\circ} \mathrm{C}$ under 95 $\%$ air $/ 5 \% \mathrm{CO} 2$. For replication, three different slice pools were prepared, each containing 3 slices, were deployed for each concentration of test compounds.

\section{Extraction of RNA and quantitative real-time polymerase chain reaction}

After 24-hour incubation with benzo[a]pyrene (1 and 5 $\mu \mathrm{M})$ alone or in the existence of PEITC $(1-25 \mu \mathrm{M})$, three slices were deployed for extracting total RNA employing NucleoSpin ${ }^{\circledR}$ RNA II followed by quantification of RNA using Nanodrop spectrophotometer at $260 \mathrm{~nm}$. For reverse transcription, RNA was primed with random hexamers using a Superscript II reverse transcriptase. cDNA was then amplified employing AbsoluteTM QPCR Mix comprising $100 \mathrm{nM}$ fluorogenic probe and $400 \mathrm{nM}$ forward and reverse primers. The reactions were performed using ABI7000 SDS Instrument (Applied Biosystems, Warrington, UK) and quantitated utilizing ABI software against a standard curve. CYP1A1 mRNA expression levels were normalized with respect to $18 \mathrm{~S}$ rRNA and expressed in percentage. The oligonucleotide sequences of the forward and reverse primers, and also probes are as below:

CYP1A1

5' primer: GCCTTCACATCAGCCACAGA 3' primer: TTGTGACTCTAACCACCCAGAATC Probe: TGGCCGTCACCACATTCTGCCTT

\section{S rRNA \\ 5' primer: CGGCTACCACATCCAAGGAA \\ 3' primer: GCTGGAATTACCGCGGCT \\ Probe: TGCTGGACACAGACTTGCCCTC}

\section{Immunoblot analysis on CYP1A apoprotein levels}

Rat liver slices were prepared as afore-mentioned and incubated in media containing a range of PEITC concentrations $(1-40 \mu \mathrm{M})$ in the existence and nonexistence of benzo[a]pyrene. Two concentrations of benzo[a] pyrene $(0.1$ and $10 \mu \mathrm{M})$ were applied in rat liver slices. Following 24-hour incubation, slices were eradicated from the medium, S9 was prepared and stored at -80 0C. Microsomal fractions were made by multi-step centrifugation when required. Protein concentration was determined according to Bradford (1976) followed by western blot analysis to ascertain whether decrease in CYP1A1 mRNA levels engages, at least in part, a drop in enzyme availability. Microsomal proteins were loaded onto SDS-PAGE $10 \%$ (w/v) and subsequently transferred electrophoretically to PVDF membrane. Immunoblot analysis was conducted via exposure to the primary antibodies followed by the compatible HRPconjugated secondary antibody. The immunoblots were then quantified using densitometry employing GeneTool software (Syngene Corporation, Cambridge, UK), with the control band labelled as $100 \%$.

\section{Statistical analysis}

All results are shown in mean \pm standard deviation. Three different slice pools, each consisting 3 rat slices were used with triplicate analyses for the determination of mRNA levels. Statistical evaluation was performed employing one-way ANOVA followed by Dunnett's posthoc analysis.

\section{Results}

\section{CYP1A1 mRNA studies}

A 24-hour incubation of precision-cut rat liver slices with benzo[a]pyrene ( 1 and $5 \mu \mathrm{M})$ alone resulting in rises of CYP1A1 mRNA levels (as expressed in 100\%); this effect was inhibited in a concentration-dependent manner by PEITC (Figure 1 and Figure 2). It is worthwhile 


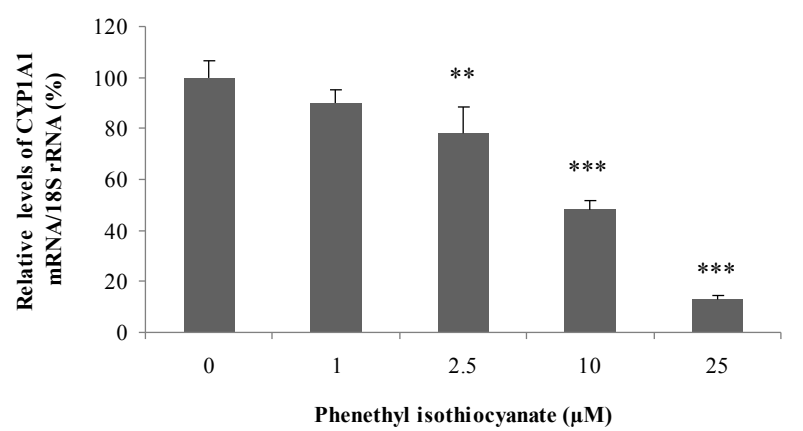

Figure 1. CYP1A1 mRNA Levels in Rat Liver Slices Exposed to PEITC in Combination with Benzo[a] Pyrene. Precision-cut rat liver slices were incubated with benzo[a]pyrene $(1 \mu \mathrm{M})$ in the presence of PEITC $(0-25 \mu \mathrm{M})$ for $24 \mathrm{~h}$. Total RNA was extracted from tissue slices and the mRNA levels of CYP1A1 were quantified by quantitative RTPCR methodology (Taqman); mRNA levels were normalized with respect to $18 \mathrm{~S}$ rRNA and expressed in percentage. Values are presented as mean $\pm \mathrm{SD}$ of three replicates, each containing 3 slices. **, ${ }^{*}<0.01 ; * * *, \mathrm{p}<0.001$ as compared to $0 \mu \mathrm{M}$ of PEITC

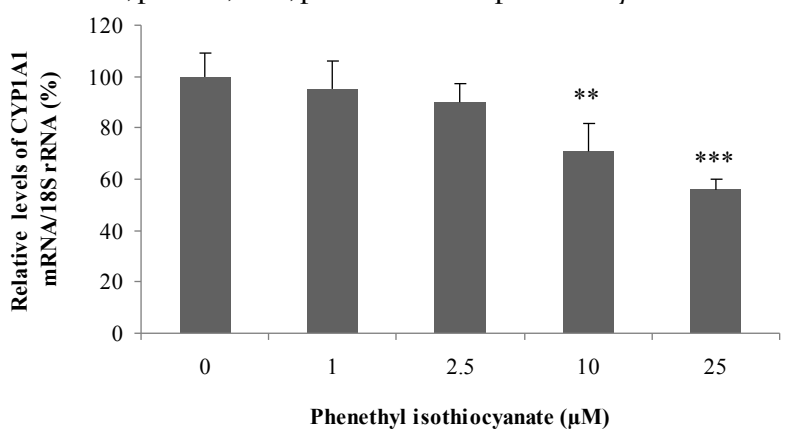

Figure 2. CYP1A1 mRNA Levels in Rat Liver Slices Exposed to PEITC in Combination with Benzo[a] pyrene. Precision-cut rat liver slices were incubated with benzo[a]pyrene $(5 \mu \mathrm{M})$ in the presence of PEITC $(0-25 \mu \mathrm{M})$ for $24 \mathrm{~h}$. Total RNA was extracted from tissue slices and the mRNA levels of CYP1A1 were quantified by quantitative RTPCR methodology (Taqman); mRNA levels were normalized with respect to $18 \mathrm{~S}$ rRNA and expressed in percentage. Values are presented as mean $\pm \mathrm{SD}$ of three replicates, each containing 3 slices. ${ }^{* *}, \mathrm{p}<0.01{ }^{* * *}, \mathrm{p}<0.001$ as compared to $0 \mu \mathrm{M}$ PEITC

stating that the inhibition of the benzo[a]pyrene-initiated induction of CYP1A1 mRNA levels was seen starting from incubation at $2.5 \mathrm{mM}$ of PEITC.

\section{CYP1A apoprotein levels}

Immunoblot analysis of CYP1A1 revealed that the inhibition of enzymatic activity was due to a decrease in enzyme availability (Figure 3). At $0.1 \mu \mathrm{M}$ benzo[a]pyrene, synergistic effect observed at the low $10 \mu \mathrm{M}$ PEITC concentration, but antagonistic effect was manifested at the higher concentrations of PEITC (Figure 3). At the $10 \mu \mathrm{M}$ benzo[a]pyrene, synergistic effect was evident at the 10 , and to lower extent, $30 \mu \mathrm{M}$ concentration of PEITC, but a marked antagonistic effect at the $40 \mu \mathrm{M}$ concentration was seen (Figure 3).

\section{Discussion}

PEITC has the ability to protect against many chemical carcinogens in different organs of animal $\begin{array}{llllllll}100 & 304 & 78 & 174 & 42 & 41 & 40 & 33\end{array}$

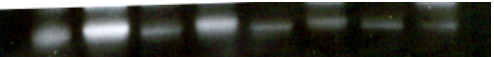

CYP1A1 $(0.1 \mu \mathrm{MBaP})$

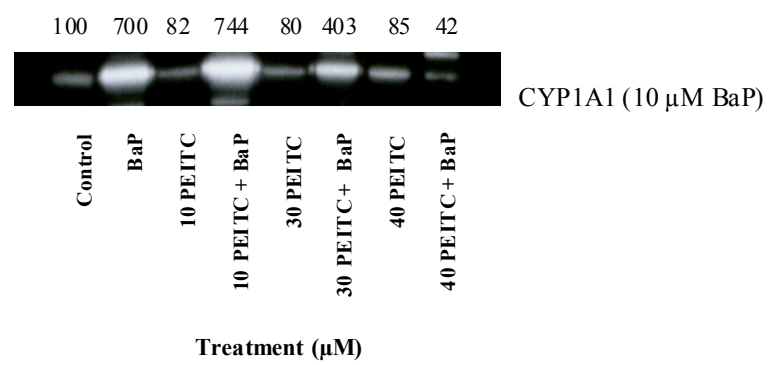

Figure 3. Effect of PEITC on Benzo[a]PyreneMediated CYP1A1 Apoprotein Levels in Rat Liver Slices. Liver slices were incubated in culture medium containing 0.1 or $10 \mu \mathrm{M} \mathrm{BaP}$ alone or in combination with PEITC (1-40 $\mu \mathrm{M})$ for $24 \mathrm{hr}$. Microsomal proteins were isolated and equal amounts of corresponding protein were loaded on to $10 \%(\mathrm{w} / \mathrm{v})$ SDS-PAGE and then transferred electrophoretically to Hybond-P polyvinylidene difluoride membrane. The immunoblot analysis was carried out utilizing mouse anti-rat CYP1A1 primary antibodies followed by the appropriate peroxidase-labelled secondary antibody. Each lane was loaded with $30 \mu \mathrm{g}$ of total protein. Values above blots show \% levels of optical density of each band relative to control

models (Wu et al., 2009). The potential basis of protecting mechanisms towards chemical carcinogens involves interference of the metabolic pathways of carcinogens by modulating enzymes, such as CYP1, which are associated with bioactivation (Conney, 2003) and inducing phase II enzymes such as GST and NQO1 (Tan et al., 2010). Following the experimental evidence indicating modulation of carcinogen-metabolizing enzymes by PEITC in human and rat liver slices as well as in vivo in rat as described in the published articles (Ioannides and Konsue 2008, Konsue and Ioannides, 2010a, 2010b), the present study was conducted to elucidate the role of PEITC as chemopreventive agent towards distinct carcinogen namely benzo[a]pyrene. This carcinogen was chosen as it was believed to contribute to human cancer risk, as important tobacco-derived and diet-derived carcinogen (Lee and Shim, 2007). Moreover, this compound is known as pro-carcinogen, requiring CYP450-mediated activation, catalyzed by CYP1A1 in the case of benzo[a] pyrene (Uppstad et al., 2010).

Benzo[a]pyrene is an important environmental carcinogen presented in cigarette smoke, industrial waste by-products (Chen et al., 2002) and food (Hecht, 1999). Average daily intake of benzo[a]pyrene ranges from non-detectable to $389 \mathrm{ng}$ per person per day depending on individual lifestyle (European Food Safety Authority, 2008). The induction of enzymes by benzo[a]pyrene is mainly to enhance its biotransformation, primarily by CYP1 especially CYP1A1 (Uppstad et al., 2010). Such induction is believed to enhance the generation of the genotoxic benzo[a]pyrene 7,8-diol-9,10-epoxide that binds covalently to cellular DNA and initiates carcinogenesis (Nebert et al., 2004). Benzo[a]pyrene is an avid ligand of the Ah receptor and this binding leads to upregulation of CYP enzyme involved in its metabolism such 
as CYP1A1 and CYP1B1 (Nebert et al., 2004; Vondracek et al., 2009). Utilizing precision-cut rat liver slices the aim of this study was to determine whether PEITC can inhibit benzo[a]pyrene-mediated enzyme induction, possibly by interfering with its interaction with the Ah receptor.

The breakdown product of glucosinolates, isothiocyanates have been shown in epidemiology studies to lower cancer risk, and their chemoprevention properties have been proven experimentally (Hecht, 2000). As electrophiles, they are likely to manipulate cellular processes through binding covalently to nucleic acids, proteins, or small molecules and may be indirectly reducing pools of cellular reductants (Nakamura and Miyoshi, 2010). A mechanistic study to determine the effect of isothiocyanates on CYP1A1 activity and expression, and Ah receptor translocation in Mcf7 cells demonstrated that this enzyme was significantly stimulated by benzo[a]pyrene, and isothiocyanates were able to inhibit the rise in activity (Skupinska et al., 2009). A view has been expressed that the inhibition of CYP1A1 enzyme may serve as a useful strategy for cancer chemoprevention (Kleiner et al., 2002).

In the previous studies, exposure of rat liver slices to PEITC led to a modest rise in CYP1A1 mRNA levels at concentration as low as $1 \mu \mathrm{M}$, and the reduction was observed at the highest concentrations employed (Abdull Razis et al., 2011). Similarly, in primary human hepatocytes both sulforaphane and PEITC raised CYP1A1 mRNA levels (Gross-Steinmeyer et al., 2004). Hepatic CYP1A1 apoprotein levels of rats administered diets containing PEITC was up-regulated at high doses with no concomitant rise in CYP1A1 activity, most probably due to the point that PEITC is a mechanismbased inhibitor (Konsue and Ioannides, 2008; Konsue and Ioannides; 2010a). In line with the ligand-binding studies (Abdull Razis et al., 2011), a benzo[a]pyreneinduced hepatic CYP1A1 mRNA levels was inhibited by PEITC at concentration dependent manner. Similar to CYP1A apoprotein levels, at the high benzo[a]pyrene concentration, synergism was seen at the 10 , and to lesser extent, $30 \mu \mathrm{M}$ concentration of PEITC, but a clear inhibition at the $40 \mu \mathrm{M}$ concentration. In agreement, it has been demonstrated that oral administration of sulforaphane to mice resulted in the inhibition of benzo[a] pyrene-induced aryl hydrocarbon receptor activation that consequently decreased cytochrome P450 enzyme activities (Priya et al., 2011).

Induction of CYP1 is known to be regulated through the ligand-activated aryl hydrocarbon receptor (AhR) (Stejskalova et al., 2011). Prior to dissociation from its ligand-binding partners, AhR translocates into the nucleus, subsequently binds to a specific nucleotide sequence of general transcription factors and initiates gene transcription of enzymes including CYP1 (Stejskalova et al., 2011). As a result of suppression of apoprotein levels, the inhibitory effects of PEITC in the current study may involve modulation of the binding of benzo[a]pyrene by PEITC, although the underlying mechanism remains to be established. On the other hand, inhibition mechanism of PEITC on CYP1A may be the result of interactions at the site of the AhR, preventing the binding of benzo[a] pyrene and/or mechanism-based inhibition leading to loss of activity.

In summary, the present study demonstrated that PEITC inhibits the benzo[a]pyrene-induced rise in hepatic CYP1A1 mRNA and apoprotein levels, and this may add to its established chemopreventive potential.

\section{Acknowledgements}

The authors would like to thank Universiti Putra Malaysia for funding this work through GERAN UPM with project no. GP-IPM/2013/9400600.

\section{References}

Abdull Razis AF, Konsue N, Dervetzoglou M, et al (2011). Phenethyl isothiocyanate, a naturally-occurring phytochemical, is an antagonist of the aryl hydrocarbon receptor. Mol Nutr Food Res, 55, 1-10.

Abdull Razis AF, Mohd Noor (2013a). Sulforaphane is superior to glucoraphanin in modulating carcinogen-metabolising enzymes in hep G2 cells. Asian Pac J Cancer Prev, 14, 4235-8.

Abdull Razis AF, Mohd Noor (2013b). Cruciferous vegetables: dietary phytochemicals for cancer prevention. Asian Pac J Cancer Prev, 14, 1565-70.

Abdull Razis AF, Mohd Noor N, Konsue N. (2014). Induction of epoxide hydrolase, glucuronosyl transferase and sulfotransferase by phenethyl isothiocyanate in male Wistar albino rats. Biomed Res Int, 2014, 391528.

Boyce A, David RM, Gooderham NJ. (2014). The mutagenic effects of 2-amino-1-methyl-6-phenylimidazo[4,5-b] pyridine in Muta $^{\mathrm{TM}}$ mouse colon is attenuated by resveratrol. Toxicol Res, 3, 197.

Bradford MM. (1976). A rapid and sensitive method for the quantitation of microgram quantities of protein utilizing the principle of protein-dye binding. Anal Biochem, 72, 248-54.

Chen SY, Wang LY, Lunn RM, et al (2002). Polycyclic aromatic hydrocarbon-DNA adducts in liver tissues of hepatocellular carcinoma patients and controls. Int J Cancer, 99, 14-21.

Conney AH. (2003). Induction of drug-metabolizing enzymes: a path to the discovery of multiple cytochromes P450.Annu Rev Pharmacol Toxicol, 43, 1-30.

European Food Safety Authority (2008). Polycyclic aromatic hydrocarbons in food. scientific opinion of the panel on contaminants in the food Chain. EFSA J, 24, 1-114.

Gross-Steinmeyer K, Stapleton PL, Liu F, et al (2004). Phytochemical-induced changes in gene expression of carcinogen-metabolizing enzymes in cultured human primary hepatocytes. Xenobiotica, 34, 619-32.

Hashemi E, Dobrota M, Till C, et al (1999). Structural and functional integrity of precision-cut liver slices in xenobiotic metabolism: a comparison of the dynamic organ and multiwell plate culture procedures. Xenobiotica, 29, 11-25.

Hecht SS. (1999). Tobacco smoke carcinogens and lung cancer. J Natl Cancer Inst, 91, 1194-210.

Hecht SS. (2000). Inhibition of carcinogenesis by isothiocyanates. Drug Met Rev, 32, 395-411.

Hecht SS. (2003). Tobacco carcinogens, their biomarkers and tobacco-induced cancer. Nat Rev Cancer, 3, 733-44.

Kassie F, Uhl M, Rabot S, et al (2003). Chemoprevention of 2-amino-3-methylimidazo[4,5-f]quinoline (IQ)-induced colonic and hepatic preneoplastic lesions in the F344 rat by cruciferous vegetables administered simultaneously with the carcinogen. Carcinogenesis, 24, 255-61.

Kleiner HE, Vulimiri SV, Reed MJ, et al (2002). Role of 
cytochrome P450 1a1 and 1b1 in the metabolic activation of 7,12 dimethylbenz[a]anthracene and the effects of naturally occurring furanocoumarins on skin tumor initiation. Chem Res Toxicol, 15, 226-35.

Kobayashi M, Otani T, Iwasaki M, et al (2009). Association between dietary heterocyclic amine levels, genetic polymorphisms of NAT2, CYP1A1, and CYP1A2 and risk of colorectal cancer: A hospital-based case-control study in Japan. Scand J Gastroenterol, 44, 952-9.

Konsue N, Ioannides C. (2008). Tissue differences in the modulation of rat cytochromes $\mathrm{P} 450$ and phase II conjugation systems by dietary doses of phenethyl isothiocyanate. Food Chem Toxicol, 46, 3677-83.

Konsue N, Ioannides C. (2010a). Modulation of carcinogenmetabolising cytochromes $\mathrm{P} 450$ in human liver by the chemopreventive phytochemical phenethyl isothiocyanate, a constituent of cruciferous vegetables. Toxicol, 268, 184-190.

Konsue N, Ioannides C. (2010b). Differential response of four human livers to modulation of phase II enzyme systems by the chemopreventive phytochemical phenethyl isothiocyanate. Mol Nutr Food Res, 54, 426-32.

Kuroiwa Y, Nishikawa A, Kitamura Y, et al (2006). Protective effects of benzyl isothiocyanate and sulforaphane but not resveratrol against initiation of pancreatic carcinogenesis in hamsters. Cancer Lett, 241, 275-280.

Lee BM, Shim GA. (2007). Dietary exposure estimation of benzo[a]pyrene and cancer risk assessment. J Toxicol Environ Health, 70, 1391-4.

Liu J, Sridhar J, Foroozesh M. (2013). Cytochrome P450 family 1 inhibitors and structure-activity relationships. Molecules, 18, 14470-95.

Nakamura Y, Miyoshi M. (2010). Electrophiles in food; the current status of isothiocyanates and their chemical biology. Biosci Biotechnol Biosc, 74, 242-55.

Nebert DW, Dalton TP, Okey AB, et al (2004). Role of aryl hydrocarbon receptor-mediated induction of the CYP1 enzymes in environmental toxicity and cancer. $J$ Biol Chem, 279, 23847-50.

Priya DKD, Gayathri R, Gunassekaran GR, et al (2011). Inhibitory effect of sulforaphane against benzo(a)pyrene induced lung cancer by modulation of biochemical signatures in female Swiss albino mice. Asian J Biochem, 6, 395-405.

Renuka Devi J, Berla Thangam E (2012). Mechanisms of anticancer activity of sulforaphane from Brassica oleracea in HEp-2 human epithelial carcinoma cell line. Asian Pac $J$ Cancer Prev, 13, 2095-100.

Skupinska K, Misiewicz-Krzeminska I, Stypulkowski R, et al (2009). Sulforaphane and its analogues inhibit CYP 1A1 and CYP 1 A2 activity induced by benzo(a)pyrene. J Biochem Mol Toxicol, 23, 18-28.

Stejskalova L, Dvorak Z, Pavek P. (2011). Endogenous and exogenous ligands of aryl hydrocarbon receptor: current state of art. Curr Drug Metab, 12, 198-212.

Tan Xiang-Lin, Shi M, Tang H, et al (2010). Candidate dietary phytochemicals modulate expression of phase II enzymes GSTP1 and NQO1 in Human Lung cells. J Nutr, 140, 1404-10.

Uppstad H, Ovrebo S, Haugen A, et al (2010). Importance of CYP1A1 and CYP1B1 in bioactivation of benzo[a]pyrene in human lung cell lines. Toxicology Letters, 192, 221-8.

Vondracek J, Krcmar P, Prochazkova J, et al (2009). The role of aryl hydrocarbon receptor in regulation of enzymes involved in metabolic activation of polycyclic aromatic hydrocarbons in a model of rat liver progenitor cells. Chem Biol Interact, 180, 226-37.

Williams TD, Lee JS, Sheader DL, et al (2000). The cytochrome
P450 1Agene (CYP1A) from European flounder (Platichthys flesus), analysis of regulatory regions and development of a dual luciferase reporter gene system. Mar Environ Res, 50, 1-6.

Wohak LE, Krais AM, Kucab JE, et al (2014). Carcinogenic polycyclic aromatic hydrocarbons induce CYP1A1 in human cells via a p53 dependent mechanism. Arch Toxicol, [Epub ahead of print]

Wu X, Zhou Qing-hua, Xu K. (2009). Are isothiocyanates potential anti-cancer drugs? Acta Pharmacol Sin, 30, 501-2. 